\title{
The Research and Design of Project Based Language Assessment System
}

\author{
Du Mojun \\ School of Foreign Languages \\ East China Jiaotong University \\ Nanchang, China \\ dumojun@163.com
}

\begin{abstract}
In recent years, many linguists have carried on a lot of researches and analysis on Project-Based Learning (PBL) from different perspectives. However, the research of Project based language assessment (PBLA) is comparatively scarce. This paper introduces how to conduct the research and design on Project Based Language Assessment System, and defines the fundamentals or the basic principles for the operation. Through a detailed analysis on PBLA and a clear comparison with other testing system, we can safely draw the conclusion that PBLA, as a new proposed notion in language testing domain, plays an important role in effectively evaluating students' language proficiency, as well as helping students improve their ability of using a language. And PBLA, with its better validity and development prospect, should arouse more linguists' attention, and the research helps to build technical code of PBLA to guide the performance of testing itself and evaluation organization.
\end{abstract}

Keywords- project- based; language testing; assessment system

\section{INTRODUCTION}

Project Based Learning (PBL) is a new teaching model, which emphasizes the authenticity of language testing, and allows us to test the language proficiency of students in real situations. It is beneficial to cultivate students' ability to solve problems and to use English as a language. In fact, the Hedge began to implement a project based language teaching in the ESL program in 1993, in his view, Project based language teaching (PBLT) is different from the task based language teaching (TBLT) or content-based language teaching. It has a longer time span, and at the same time, it is required to integrate language learning with other subjects, emphasizing the language learners to reflect on the learning process and results.

Although the project based language learning has begun to be widely used in the field of basic education, higher education and other fields, the research of Project Based Language Assessment is pretty scarce, and it's still in the experimental stage. Considering the backwash effects of language teaching, the research should be carried out early. Project-based Language Assessment (PBLA) has slowly emerged to challenge the traditional itemized formbased assessment. The essence of PBLA is "learning by doing", "Promoting learning by evaluation", a process during which learners engage in naturalistic learning processes through experiencing and exploring language, through cycles of analysis and synthesis so as to develop their own interlanguage system.

\section{THEORETICAL BACKGROUND}

Thirty years of studies on language testing have revealed that authenticity in language assessment has been an important aspect of the experts' attention. Encouraging learners to reflect on their performance can contribute to the development of the meta-cognitive strategies of planning, monitoring and evaluating, which are seen as important for language learning (O'Malley \& Chamot, 1990) [12]. Meanwhile, for the formative evaluation, it becomes a process of ongoing self-assessment and peer assessment. Learner-based evaluations of tasks can help teachers decide whether to use similar tasks in the future or look for a different type. Along with the development of communicative language teaching method since 1980s, Bachman (1990) proposed the basic principle of communicative language testing design, and laid a solid foundation for the establishment of communicative language testing theory[1]. Bachman believes that communicative language testing should embody the three principles, namely the principle of communication, the principle of task and the principle of meaning. Communicative language testing is to measure students' ability of English language proficiency through real communicative tasks under the real or close to real language context. Thus, the research on authenticity in language testing is given the priority among priorities incommunicative language testing.

After theory of communicative competence has been proposed, Bachman and Palmer put forward some new concept in communicative testing, such as Usefulness, Construct Validity, Authenticity, and Instructiveness. Bachman also point out that communicative language testing is a kind of behavioral testing, which is used to measure the students' ability of using language knowledge in real or close to real situations.

In 2004, Bachman published his book named Fundamental Considerations in Language Testing, a book again gave a detailed elaboration on language competence, validity and authenticity, as well as the factors which affecting test performance with particular emphasis on the importance of authenticity of language testing. In his book, a new approach to the acquisition of linguistic competence is presented, and a new method based on the task of language acquisition is proposed. Bachman presented new requirements for the empirical study of language testing, and develop it into test validation theory.

In China, Han Baocheng (1995)[5], Jia Yidong (2010), Xu Qilong (2012) and so on, have discussed these problems, and determined that the authenticity of the 
situation and the authenticity of the communication of these two criteria should be taken into consideration while designing the tests and evaluating the candidates.

\section{THE PROBLEMS AND SOLUTIONS IN THE CONTEMPORARY TEST}

In recent years, although the English language curriculum design has shifted to the students-centered communicative teaching mode, but this trend of development has not been reflected in the mainstream of English teaching and testing. The current English test is in a way that is to test the students' ability to use the English language (Luo Shaoqian, 2009)[9]. At the same time, it is very difficult for teachers to fully understand the requirements of National English Curricular Standard the (NECS), which is often lack of practical cases and samples, failed to use examples to explain the requirements of different levels. Therefore, when teachers are designing examination papers, most are based on their own experience to construct their own understanding, but neglect the purpose, content and process of learning.

This shows that there are many problems in the current language testing evaluation system design: 1) The separation of theory and practice, 2) English test failed to reflect the students' critical thinking, creativity and innovation ability, 3) In terms of testing method, too much emphasis is put on scientific and instrumental function, and humanistic characteristics are failed to reflect. 4) With regard to the from of examinations, the task or project design, validity and reliability, technology and specialization of test design need to be strengthened during the design process of test papers.

There is now a general consensus in language teaching and testing that the use of authentic materials in the process is beneficial to stimulating the interests of the learners. However, the notion of authenticity has largely been restricted to discussions about texts. Task authenticity should cover interpretational authenticity, practice authenticity and situational authenticity as well. Regarding task goal, Skehan [13] states clearly three long-term pedagogic goals, namely, accuracy, fluency and complexity. Chinese language teachers have no difficulty in understanding the three goals. But the problem lies in that they do not know how to associate the macro-goal with every text and every unit [5]. Language assessment is just a simple method which the teachers can use to collect feedback from the students, on how well students are learning what they are being taught in or out of the classroom. Performance assessment is defined as a systematic attempt to measure a learner's competence to use previously acquired knowledge in the process of solving problems or completing specific projects. Performance assessment thus differs from traditional paper-and-pencil tests in that the primary focus is to get an accurate picture of students' communicative abilities.

Therefore, project based language test came into being under the circumstance. In fact, it is essentially language test in the real world situation, which can be used to evaluate the students' practical language competence. This test pattern can evaluate the language form of students and the different results of different contexts. It can also be used to evaluate the results and effectiveness of the target language regardless of students' differences of language in use caused by different language context and language form. Project based language assessment can make the language evaluation form more diverse, all methods that can detect the students competence in the actual language application should be promoted and applied, so that students can use English flexibly and effectively, and become proficient English speakers.

\section{BASIC PRINCIPLES FOR TBLA}

\section{A. Validity and reliability}

Validity and reliability are two key parameters in the evaluation tests. The so-called validity refers to the degree of testing and evaluation of the test objectives, and the reliability of the test is mainly refers to whether the test procedure is coherent, if the test results are different, the credibility of the test will be very low. The validity of the two is the most difficult to control. Due to the limitation of the length and space, this paper mainly analyzes the test validity only.

1) Face validity: Face validityrefers to the test's "surfice credibility or public acceptability" (Ingram 1977:18)[6], and is frequently dismissed by testers as bening unscuientific and irrelevant(see Stevenson 1985)[13]. Only when the test is considered to be effective, the participants may play their best in the test and make the appropriate response to the test project. If the participants take a negative attitude to the test, then their attitude will affect their performance in the test, and lead to the test scores are unrelated. So testing should have a high surface validity.

2) Content validity: Content validity is the representative or sampling adequacy of the content - the substance, the matter, the topics - of a measuring instrument. (Kerlinger 1976:458)[8]. Project based language testing should cover all that is expected to be completed by the syllabus. Although the current syllabus of English language teaching is to cultivate students' communicative competence in the first place, but the emphasis is still focused on the accuracy of the speech. Therefore, if we take the project-based syllabus as the basis to observe the current English exam, we will find that most of the content validity of the test is difficult to meet the standard.

3) Construct validity: Construct validity was used to measure the performance of a subject in a test that could be interpreted as an indicator of a characteristic or quality. Undoubtedly, the structure validity is the most difficult to grasp. Because the structure itself is abstract, the internal relevance of the test is regard as a measurement of the construct validity. The internal relevance of the test is to test the correlation between each component. A test has included a series of different component, and each component of the measurement represents a different quality. these different qualities together constitute the panorama of language ability. Therefore, the correlation coefficient between the various components should be comparatively low, if too much means that two 
components actually test is homogeneous, then it is redundant and should be eliminated from the PBLA.

\section{PREPARATION AND TESTING PROCEDURE OF PBLA}

\section{A. Evaluation method}

The traditional language testing is a kind of large-scale language testing, and its testing time, scoring standards and score interpretation can maintain a high degree of consistency. The advantage of the traditional assessment is crystal clear: high efficiency, high Validity. On the contrary, communicative language assessment attaches much importance to the cultivation of student's communicative competence.

Carrooll (1981)[2] determined that "the criterion for success lies in formal correctness but in communicative effectiveness." David Nunan also pointed out that testing should be closely related to the objectives of teaching in the communicative testing, in other words, that's "to test what we taught". However, the focus of our testing still goes to the accuracy of the language, that is, the right language. Taking this standard to look at our current examination, the drawback is self-evident: first, the gap between the examination and teaching will seriously affect the degree of attention and participation of students in the curriculum teaching; second, teachers are very difficult to obtain information to refer to their teaching process and make adjustments in time.

Project based language assessment is much more flexible and diverse, and easy to operate. Various quantitative data analysis and qualitative method for language testing can be combined to evaluate the students' performance during examination. The problem is that the score is more subjective, therefore raters need to be trained before the rating in order to keep the same standard of rating. The preparation of project based language testing can be classified as interviews, teaching syllabus, and investigation documents, etc.. In the late stage of the test, specific project test tasks will be arranged. With the completion of the project, raters will evaluate the results and performance of the participants. In essence, the project language assessment is a "dynamic evaluation" type.

\section{B. Procedure of Project Based Language Testing}

- Specific Plan: the test needs to be completed within the specified time. According to the time needed for different projects, it is necessary to make an overall plan or detailed arrangement in the first week, for example, first, the introduction to PBLT, the relevant topics. Students can start their research based on the topics given by the teachers, or the topics which they are interested in. generally, Students are required to complete a small project in pairs for this class's homework assignment that must be turned in by the fourth class.

Project implementation: According to the project implementation plan, the students start their project research after class. The project can be altered or adjusted when there is an actual situation change during the implementation process. At the same time, there is a need to have a detailed research progress. The teacher should give more necessary instructions in English language skills. This stage is the core part of the project testing. Students need to record the whole process and put forward the hypothesis at the beginning of the research with the help of some research tools and methods to collect data, then the data will be processed. When the project is completed, the hypothesis will be verified with the solution to the problem. After the implementation of the project, students must write a research report, and make oral presentations to demonstrate their own research results.

\section{THE CONSTRUCTION OF EVALUATION SYSTEM AND} ITS ELEMENTS

\section{A. Rating scale}

Encourage students to present various results. The final product for the project is submitted by students, which can be the research report, the survey report, or the type of literature show. In short, it is necessary to follow the students' interest and willingness to produce all kinds of results.

\section{B. Project evaluation}

According to the performance of students in all aspects of the evaluation, Teachers (Raters) evaluate participants' performance. Unlike the traditional testing methods, Project based language assessment is an formative language assessment. In order to evaluate the participants fairly, it needs to be combined with qualitative evaluation and quantitative evaluation.

\section{Raters (assessment team members)}

Evaluation can be done by experts and teachers. Teachers can observe the skills, knowledge and methods used by students (the participants) in the course of project learning, and examine what skills they have acquired and how about the collaboration among the team members. Eventfully, the final evaluation will be given according to the components of the project assessment.

\section{Content Evaluation}

The contents of the evaluation are mainly from the following aspects: the selection of research projects; the performance of students in group testing; the cooperation between the team members in the process of testing; the arrangement of the plan and time span; and the final products of the research and oral presentation, especially emphasizing the acquisition of new knowledge and mastery of new skills, or the technical and artistic quality; the documents for research, including all the original data, activity logs, questionnaires, interview records, note for studies. All the mentioned above should be taken into consideration during the evaluation process.

\section{CONCLUSION}

Research learning is a relatively mature learning style in European and American countries, project based learning is one of the most common use of the two teaching modes, however project based language assessment is still in the exploration stage. In China, the educational circles is also under the same case for the 
project based language assessment, this is mainly due to the limitation of current examination oriented education system in our country. At the same time, it takes a long time to design project based language assessment, and it is unlikely to be implemented in the classroom environment. Compared to the traditional paper and pencil test method, it is difficult to accept by the domestic education sector in the short term. Therefore, as a new type of language teaching, project based language assessment (PBLA), still has a long way to go. As the related researchers, we should promote the research and application of PBLA, allowing students to take the initiative in exploring the world and cultivating their creative thinking and the capability to solve the real world problems.

\section{REFERENCE}

[1] Bachman L F. Fundemental Considerations in Language Testing [M]. Oxford: Oxford University Press, 1990:23-30

[2] Carroll, B. Testing Communicative Performance [M]. Oxford: Pergamon, 1981

[3] D. R. Carless, "Implementing task-based learning with young learners", ELT Journal, 2002, 56 (4), pp. 389-395

[4] D. Nunan, Designing Tasks for the Communicative Classroom[M] Cambridge: Cambridge University Press. 1989.

[5] Han Baocheng. The Language Testing Theory Mode of Lyle. F Bachman[J]. Foreign Language Teaching and Research Press, 1995(1):55-60.
[6] Ingram, E. 1977. Basic Concepts in Testing. In J.P.B. Allen and A. Davies(eds.), Testing and Experimenttal Methods. Oxford: Oxford University Press.

[7] J. Willis, A Framework for Task-based Learning. London: Longman. 1996(1):96-120.

[8] Kerlinger, F.N. 1973. Foundations of Behaviral Research. New York: Holt, Rinehart and Winston.

[9] Luo Shaoqian. Re-examing Factors That Affect Task Difficulty in TBLA[M]. Shanghai Foreign Education Press, 2009:50-61.

[10] M. Breen, "Authenticity in the language classroom", Applied Linguistics, 1985, 6 (1), pp. 60-70.

[11] M. Breen, "Authenticity in the language classroom", Applied Linguistics, 1985, 6 (1), pp. 60-70.

[12] O'Malley, J. \& Chamot, A. Learning Strategies in Second Language Acquisition $[\mathrm{M}] \backslash$. Cambridge: Cambridge University Press, 1990.

[13] P. Skehan, "A framework for the implementation of task-based instruction", Applied Linguistics, 1996, 17 (1), pp. 38-62.

[14] Stevenson, D.K. 1985. Authenticity, Valiidity and a Tea Party. Language Testing 2 (1):41-7.

[15] R. Ellis, Task-based language learning and teaching[M], Oxford University Press, Oxford, 2003.

[16] Weir, C, J. Understanding and Developing Language Tests[M]. Longdon Prentice Hall, 1993:64.

[17] W. Littlewood, "The task-based approach: some questions and suggestions", ELT Journal, 2004, 58 (4), pp. 319-326. 